\title{
POLÍTICA: INSTRUMENTO DE DEMOCRATIZAÇÃO DA SOCIEDADE
}

\author{
Sarah Maria Linhares de Araújo*
}

RESUMO: O presente texto visa demonstrar a importância do espaço público e da concretização da política na sociedade. É por meio das ações políticas que direitos e garantias são conquistados e preservados. Para além disso, a democracia também é instrumentalizada pela política, não significando em momento algum que ser democrático é conceber idéias iguais.

\section{INTRODUÇÃO}

No mundo atual, a sociedade encontra cada vez menos tempo para preocupações com a política, o que ocasiona uma sensível diminuição no chamado espaço público, uma vez que é neste que ela se concretiza. Ao analisar a teoria política de Hannah Arendt, fundamentos sólidos serão encontrados e a partir destes poder-se-á demonstrar a importância da política dentro da sociedade. Além disso, por meio da teoria arendtiana subsídios para uma revalorização do espaço público serão encontrados.

* Mestranda em Direito do Estado pela Universidade Federal do Paraná.
RÉSUMÉ: The work has the objective the show the importance of the public space and the concretization of the politic in the society. Are beyond politics actions that rights and guaranties are acquired and kept. The democracy is the way to show the politic, this is not means that to be a democratic is to have the same ideas.

André Duarte, ao retratar o pensamento de Hannah Arendt, demonstra que “(...) o traço marcante da modernidade é o esquecimento da política, seja em função do crescente emprego dos meios tecnológicos da violência, aspecto em relação ao qual os totalitarismos de esquerda e de direita constituem instâncias-limite (...)"1

Outrossim, o presente trabalho também trará a teoria política de Carl Schmitt e Chantal Mouffe no que se refere aos efeitos causados pelo liberalismo nos últimos anos.

${ }^{1}$ DUARTE, André. Hanna Arendt e a modernidade: esquecimento e redescoberta da política. In: CORREIA, Adriano. Transpondo o abismo: Hanna Arendt $e$ a filosofia e a política. Rio de Janeiro: Forense Universitária, 2002. p. 55-56. 
Por derradeiro, cabe demonstrar que pelo fato de existir, nos últimos anos, um esquecimento da política, isso tem como conseqüência a enorme abertura para que abusos sejam cometidos, pois a política, conforme será visualizado, é requisito para a democracia.

\section{A POLÍTICA COMO CONDIÇÃO HUMANA}

Hannah Arendt ${ }^{2}$ em sua obra "A Condição Humana" elenca que o homem possui três atividades fundamentais, que são por sua vez: o labor, o trabalho e a ação. No que se tange ao labor, como o próprio nome denota, este se refere à dor e é por meio dele que as necessidades biológicas humanas são satisfeitas. Silvana Winckler, ao estudar Hannah Arendt, demonstra que o labor é “tudo que é necessário para a realização do ciclo de uma existência e para garantir a continuidade da espécie". ${ }^{3}$

Dessa feita, o labor estaria intimamente relacionado à natureza e, conseqüentemente, teria semelhança com aquilo que fazem os animais. Já no que tange à condição humana do trabalho, este se dirige à mundanidade e é mediante a concretização do trabalho que um mundo artificial é criado. Pela realização do trabalho, o homem ganha ares de deus, pois estaria em um processo de criação.

Por fim, a ação é a atividade fundamental que identifica o homem como ele é, tendo

2 ARENDT, Hanna. A condição humana. 10. ed. São Paulo: Forense Universitária, 2005. p.15.

WINCKLER, Silvana. Contribuições de Hanna Arendt para a teoria política. In: WOLKMER, Antonio Carlos (Org.). Introdução à história do pensamento político. Rio de Janeiro: Renovar, 2003. p. 424 em vista que a ação somente acontece na presença de outros seres humanos. Nesse sentido, Hannah Arendt elucida que "Só a ação é prerrogativa exclusiva do homem; nem um animal nem um deus é capaz de ação, e só a ação depende inteiramente da constante presença de outros". ${ }^{4}$

O homem ao mesmo tempo em que é igual é também diferente de outro homem e a ação, bem como o discurso, são os meios pelos quais as diferenças conseguem ser superadas. Dadas às diferenças que existem entre os homens, pode-se concluir que no mundo humano existe a característica da pluralidade.

Hannah Arendt considera a ação humana num alto grau de relevância e, assim, a filosofa política expressa o fato de ser “(...) com palavras e atos que nos inserimos no mundo humano; e esta inserção é como um segundo nascimento, no qual confirmamos e assumimos o fato original e singular do nosso aparecimento físico original". ${ }^{5}$ A importância da ação é tão elevada que, conforme os ensinamentos da filosofa política, quando o homem age, ele estaria nascendo novamente, ou seja, é por meio dela que ele se insere no mundo.

É imprescindível que se tenha consciência da importância da ação a fim de se compreender a política, tendo em vista que esta se realiza por meio de ação e discurso. O homem, conforme lições de Aristóteles, é um animal político, justamente pelo fato de a política ser elemento essencial para caracterizar a vida como humana.

\footnotetext{
4 ARENDT, Hanna. “A condição....”, p. 31.

Ibid, p. 189.
} 
Visualizada a importância da política na vida do ser humano, retorna-se à questão de como a política vem sendo sobrepujada pela modernidade. Com o advento da era moderna, o mundo modificou-se radicalmente, houve o chamado processo de desencantamento, conforme a teoria de Max Weber, no qual houve uma ruptura da magia e todo o pensamento passou a ser racionalizado.

Existem diversas teorias sobre a modernidade, alguns teóricos como Anthony Giddens entendem que a humanidade ainda está vivendo na era moderna. O referido teórico defende que a sociedade estaria mais especificamente na alta modernidade, e para ele, "Nós não nos deslocamos para além da modernidade, porém estamos vivendo precisamente através de uma fase de sua radicalização". ${ }^{6}$ Contudo, outros teóricos, como Boaventura de Souza Santos, ${ }^{7}$ acreditam que a modernidade já foi ultrapassada e vive-se, então, em uma pós-modernidade.

Hannah Arendt defende que a era moderna terminou no século XX e isso fica bem claro quando ela coloca que “(...) a era moderna não coincide com o mundo moderno. Cientificamente, a era moderna começou no século XVII e terminou no limiar do século $\mathrm{XX}(\ldots){ }^{\prime} .8$

Diante deste quadro pós-moderno ou até mesmo moderno, como queiram alguns, observa-se a explosão das sociedades de massas, que acaba destruindo as esferas

6 GIDDENS, Anthony. As conseqüencias da modernidade. São Paulo: UNESP, 1991. p. 57.

7 SANTOS, Boaventura de Souza. Pela mão de alice: o social e o político na pós-modernidade. 10. ed. São Paulo: Cortez, 2005.

8 ARENDT, Hanna. “A condição....”, p. 13-14. públicas e privadas, além de extinguir a própria pluralidade, que é característica do ser humano.

A diferença que marca a espécie humana entra em crise, conseqüentemente a ação também, pois ela é o meio pelo qual as diferenças aparecem e entram em debate. Com uma crise no campo da ação, haverá uma decadência no âmbito da política, uma vez que esta depende daquela.

Além disso, outros fatores contribuem para a crise do espaço público e privado. Nesse sentido, analisa-se a lição de Hannah Arendt ao demonstrar que

(...) o processo de alienação do mundo, desencadeado pela expropriação e caracterizado por um crescimento cada vez maior da riqueza, pode assumir proporções ainda mais radicais somente se lhe for permitido seguir a lei que lhe é inerente. Pois os homens não podem ser cidadãos do mundo como são cidadãos dos seus países, e homens sociais não podem ser donos coletivos como os homens que têm um lar e uma família são donos de sua propriedade privada. A ascensão da sociedade trouxe consigo o declínio simultâneo das esferas pública e privada; $(\ldots)^{9}$

Observa-se, então, que a ausência de fronteiras, fenômeno decorrente da globalização, também é fator que acaba ocasionando a crise do espaço público, pois conforme se depreende do texto de Hannah Arendt o cidadão do mundo não possui a mesma cidadania que é presenciada dentro de seu Estado-nação. Conseqüentemente, quando não há cidadania, não existem direitos políticos.

A política, conforme exposto, ocorre dentro do espaço público, daí a relevância de se preservar este ambiente, sendo que

\footnotetext{
$9 \quad$ Ibid, p. 269.
} 
uma das formas de conservar tal esfera é o acontecimento da própria política. Hannah Arendt demonstra muito bem tal fato em sua obra "A Condição Humana" ao descrever como a política era tida como atividade essencial na Grécia Antiga e como acontecia a cidadania nesta época, uma vez que os cidadãos eram somente aqueles que exerciam atividade política.

Deve ficar claro que a filosofa política em momento algum de sua obra busca um retorno ao mundo helênico, mas este é utilizado como parâmetro para que o espaço público seja valorizado na atualidade. Assim sendo, o presente trabalho apresentará algumas noções e diferenciações entre o público e o privado, tendo como marco teórico a filosofia política de Hannah Arendt.

O espaço privado, na Grécia Antiga, era o lar, possuindo um caráter de santidade, pois somente o homem que tivesse uma propriedade privada é que poderia participar dos assuntos da polis, situando-se assim no mundo. Na esfera do lar é que as necessidades eram satisfeitas, portanto, a atividade do labor é figura que marca o âmbito privado, já que ele se encontra intimamente relacionado ao contentamento de necessidades e, portanto, à preservação da espécie.

O espaço público, contrariamente, do espaço privado era a esfera da liberdade. Vale esclarecer que a liberdade concebida na Grécia Antiga possui um conceito diferente daquela que é idealizada na atualidade. Chantal Mouffe, ao citar as lições de Benjamin Constant, demonstra que a “(...) «liberdade dos modernos» consiste no gozo pacífico da independência pessoal e que isso implica a renúncia à «liberdade dos antigos», a participação activa no poder colectivo, porque esta conduz a uma subordinação do indivíduo à comunidade."10

Assim, ser livre era ser um cidadão nos postulados da Grécia antiga, pois somente o cidadão participava dos assuntos políticos. A liberdade dos antigos é também conhecida por um conceito de liberdade positiva, assim sendo, logicamente, a liberdade dos modernos terá uma concepção de liberdade negativa.

Dando continuidade à reflexão do espaço público, o homem, que estava situado na esfera pública, tinha ultrapassado a fase das necessidades e dedicar-se-ia à atividade humana da ação, pois ele exercia a atividade política. Hannah Arendt descreve que "Ser político significava atingir a mais alta possibilidade da existência humana; mas não possuir um lugar próprio e privado (como no caso do escravo) significava deixar de ser humano". ${ }^{11}$

Havia, então, uma valorização do espaço público na Grécia antiga, mas isso não significava que existiria um desprezo pelo âmbito privado, pelo contrário, para participar do espaço público deveria o cidadão ter sua propriedade privada. Quando se pensa em atividade política que era exercida na polis, deve-se ter em mente que ela era realizada por meio de palavras e nunca por coerção, já que este tipo de atitude era restrito à esfera privada, na qual não se concebia a liberdade. Eis mais uma diferença que existia entre o público e o privado.

O político deveria ser desapegado de todas as necessidades materiais, inclusive da própria vida, como bem demonstra Hannah

${ }^{10}$ MOUFFE, Chantal. O regresso do político. Lisboa: Gradiva, 1996. p. 56.

11 ARENDT, Hanna. “A condição...”, p. 74. 
Arendt: "Quem quer que ingressasse na esfera política deveria, em primeiro lugar, estar disposto a arriscar a própria vida; o excessivo amor à vida era um obstáculo à liberdade e sinal inconfundível de servilismo. A coragem, portanto, tornou-se a virtude política por excelência (...)". ${ }^{12}$

Fazendo uma associação do político grego com a sociologia, isso remonta à teoria de Max Weber da política como vocação, na qual o referido sociólogo defende que o político deveria ser vocacionado para exercer tal atividade e não atuar como um mero funcionário, pois, se dessa maneira agisse, isso desvirtuaria a política.

Max Weber leciona que "Podemos dizer que três qualidades destacadas são decisivas para o político: paixão, senso de responsabilidade e senso de proporções" ${ }^{13}$ Assim, o político, na visão weberiana, seria o indivíduo que agiria com responsabilidade em prol do bem comum, ou seja, atuaria dentro do espaço público.

Ainda no que se refere ao espaço público, este é o local da exteriorização dos atos, onde os homens mostrarão quem são, diferentemente, do que ocorre com a esfera privada, espaço em que atitudes são ocultadas.

Por fim, ainda há uma terceira categoria na filosofia de Hannah Arendt que é o social. Com a ascensão do social, a esfera privada sofre um desvirtuamento e perde a sua característica básica que era a "necessidade". Começa, então, a existir uma crise na diferenciação que existia, anteriormente,

\footnotetext{
12 Ibid, p. 45.

13 WEBER, Max. Ensaios de sociologia. 5.ed. São Paulo: LTC Editora, 1982. p. 80.
}

entre o público e o privado, o que ocasionará inúmeros problemas no exercício da política, cuja finalidade é a realização do bem comum.

No processo de crise, atitudes em prol de interesses individuais começam a ser exercidas na esfera pública, o que acarretará um enorme prejuízo ao conceito de democracia e, conseqüentemente, ao exercício de direitos.

\section{A POLÍTICA E O LIBERALISMO}

Compreendido o fato de que a modernidade teve como uma de suas conseqüências o conflito na identificação do espaço público e do privado, passa-se, então, ao estudo do liberalismo sob a visão de Carl Schmitt e Chantal Mouffe.

Primeiramente, estudar-se-á a noção de amigo e inimigo que decorre da teoria política de Carl Schmitt para a compreensão de sua teoria política. O referido teórico entende que a diferenciação entre amigo e inimigo é de fundamental relevância para que fique delimitado o que vem a ser a política e esta, por sua, vez é pré-condição para a existência do Estado.

Carl Schmitt, ao iniciar a sua conhecida obra "O conceito do político", afirma que: "O conceito do Estado pressupõe o conceito do político. Estado, segundo o uso lingüístico atual, é o status político de um povo organizado numa unidade territorial". ${ }^{14}$ Assim, para o teórico em estudo, Estado não existe sem política, daí decorre a importância do estudo da política.

\footnotetext{
${ }^{14}$ SCHMITT, Carl. O conceito do político. Petrópolis: Vozes, 1992. p. 43.
} 
E política, para Carl Schmitt, tem a noção de amigo e inimigo, sendo que tal peculiaridade fica confirmada quando o teórico afirma que "O fenômeno do político apenas pode ser compreendido mediante a referência à real possibilidade do agrupamento amigo-inimigo". ${ }^{15}$

Carl Schmitt não descreve quem é o amigo, mas delimita muito bem o campo do inimigo, e a partir de tal delimitação pode-se concluir o que é o amigo, sendo certo de que este não é identificado, tampouco certificado com tanta facilidade em decorrência da ausência de conceito e definição. O inimigo, então, "Não precisa ser moralmente mau, não precisa ser esteticamente feio; não tem que surgir como corrente econômico (...)", ${ }^{16}$ "Ele é justamente o outro, o estrangeiro bastando à sua essência que, num sentido particularmente intensivo, ele seja existencialmente algo outro e estrangeiro". ${ }^{17}$

Nesse sentido, é a partir da relação antitética que a política é estabelecida e, portanto, o Estado é delimitado. Outra questão muito importante ainda no que tange ao inimigo foi destacada por Vera Karam de Chueiri, "O inimigo é somente o inimigo público, pois tudo que tem relação com uma tal coletividade de homens, particularmente com uma nação inteira, torna-se público graças à tal relação". ${ }^{18}$

15 Ibid, p. 61.

${ }^{16} \mathrm{Ibid}_{\text {s p. }} 52$.

${ }^{17}$ Id ibid.

${ }^{18}$ CHUEIRI, Vera Karam. Nas trilhas de Carl Schmitt (ou nas teias de Kafka): soberania, poder constituinte e democracia (radical). In: FONSECA, Ricardo Marcelo (Org.). Repensando a teoria do estado. Belo Horizonte: Fórum, 2004. p. 357.
No mesmo sentido, leciona Bernardo Ferreira quando demonstra que "O antagonismo entre amigo e inimigo possui um caráter público. Trata-se de uma contraposição que opõe coletividades e não adversários privados. $\mathrm{O}$ inimigo político é em primeiro lugar um inimigo público (...)". ${ }^{19}$

Daí já se pode perceber a importância do conceito de espaço público, muito bem demonstrado por Hannah Arendt para a existência da política, uma vez que na teoria schmittiana o conceito de inimigo é delimitado no âmbito da esfera pública, ou seja, é referente ao espaço estatal. E tal delimitação é lógica, uma vez que a política é fenômeno público, não devendo, desta feita, ser levado em consideração questões particulares.

Ainda no que se refere ao inimigo no conceito de Carl Schmitt, a identificação deste é de alta relevância e ele é combatido, conforme Bernardo Ferreira, "Não é por ser moralmente mau que o outro vem a ser encarado como inimigo, mas porque essa sua condição moral se apresenta para mim como uma ameaça à minha forma de vida". ${ }^{20}$ Assim, identificar e combater o inimigo é uma maneira de autopreservação.

Todavia, ao contrário do que se possa pensar, o inimigo é necessário para constituição da própria identidade e para o acontecimento da política. Mais uma vez, Bernardo Ferreira elucida como Carl Schmitt pensa sobre o inimigo: "Assim, o conflito é, para ele, a condição da associação política.

${ }^{19}$ FERREIRA, Bernardo. O risco do político: crítica ao liberalismo e teoria política no pensamento de Carl Schmitt. Belo Horizonte: Editora UFMG, 2004. p. 41.

${ }^{20}$ Ibid, p. 43. 
$\mathrm{Na}$ análise de Schmitt, a inimizade é claramente o momento determinante da constituição da identidade coletiva. Esta última pressupõe uma definição de si em relação ao outro e, portanto, a afirmação daquilo que é central na definição de si próprio a partir da ameaça que o outro parece representar" ${ }^{21} \mathrm{e}$, por fim, afirma que "Schmitt pensa contra um adversário, mas também através dele". ${ }^{22}$

Observadas as principais questões atinentes ao conceito de inimigo na teoria schmittiana, cabe esclarecer quem é o real inimigo para Carl Schmitt. Para o teórico, o liberalismo representa o real inimigo existente na sociedade e tal fato fica evidenciado quando Carl Schmitt afirma que "O liberalismo decerto não negou radicalmente o Estado, mas por outro lado também não encontrou nenhuma teoria positiva do Estado e nenhum reforma própria do Estado, mas procurou, isto sim, prender o político ao ético e subordina-lo ao econômico;". ${ }^{23}$

Em sua obra "O conceito do político", Carl Schmitt demonstra várias vezes a supremacia do interesse econômico sobre o político no que se refere à teoria liberal e afirma que "O pensamento liberal contorna ou ignora, numa maneira sumamente sistemática, o Estado e a política e em vez disso se movimenta em uma polaridade típica, que sempre retorna, de duas esferas heterogêneas a saber, de ética e economia, espírito e negócio, cultura e propriedade".

\footnotetext{
${ }^{21}$ Ibid, p. 44.

${ }^{22}$ Ibid, p. 49.

${ }^{23}$ SCHMITT, Carl. “O conceito...”, p. 88.
}

O que se pode observar a partir da teoria schmittiana é que o liberalismo acarreta um enfraquecimento na política e, conseqüientemente, no Estado, tendo em vista que os dois encontram-se intimamente relacionados, necessitando um da presença do outro para sua sobrevivência. Enrique Serrano Gómez ao teorizar sobre Carl Schmitt demonstra o mesmo pensamento, qual seja, "Para Carl Schmitt, el proceso de modernización ha conducido al triunfo del mercado sobre el Estado". ${ }^{24}$

A partir da situação descrita por Carl Schmitt se constata uma enorme prevalência do mercado, ocasionando, desta feita, um esquecimento no que se refere à política. Boaventura de Sousa Santos, ao descrever a modernidade e seus efeitos, retrata teoria semelhante àquela demonstrada por Carl Schmitt e descreve que "Em vez de um desenvolvimento harmônico dos três princípios da regulação - Estado, mercado e comunidade -, assistimos geralmente ao desenvolvimento excessivo do princípio do mercado em detrimento do princípio do Estado e do princípio da comunidade". ${ }^{25}$

Assim, verifica-se que no decorrer dos anos, a situação agravou-se cada vez mais. As questões econômicas cada vez tomam um grau de vultuosidade maior, fazendo com que assuntos e temas importantes sejam cada vez mais sociedades no âmbito da sociedade.

\footnotetext{
${ }^{24}$ GÓMEZ, Enrique Serrano. Consenso y conflicto-Schmitt, Arendt y la definición de lo político. México: Centro de Estudios de Política Comparada, AC, 1998. p. 21.

${ }^{25}$ SANTOS, Boaventura de Sousa. A crítica da razão indolente: contra o desperdício da experiência. São Paulo: Cortez, 2005. p. 56.
} 
A dúvida que pode surgir é como o liberalismo pode ser tão prejudicial à sociedade?

O liberalismo prega por uma suposta neutralidade, que é absolutamente combatida por Carl Schmitt. Bernardo Ferreira discorre sobre o fato de que "As neutralizações liberais não seriam propriamente neutras, mas sim o resultado de escolhas e posições que justificam a idéia de que, no fim das contas, não há escolha a ser feita ou posição a ser tomada". ${ }^{26}$

Na realidade, a neutralidade do liberalismo busca por uma valorização da economia, uma vez que para esta prevalecer, segundo a teoria liberal, o Estado deve ser o mínimo, o que, conseqüentemente, acaba trazendo consequiências graves ao seio político. Carl Schmitt descreve como o Estado ao renunciar determinados poderes, acaba renunciando a si mesmo: "Um Estado que numa época econômica renuncia a reconhecer e dirigir por si mesmo as condições econômicas tem de se declarar neutro às questões e decisões políticas e com isso renuncia a sua pretensão de dominar". ${ }^{27}$

A neutralidade do liberalismo não existe, pois detrás deste véu, escondem-se, muitas vezes, escolhas individualistas em prol de interesses econômicos e que são extremamente prejudiciais ao bem comum da sociedade. Com a neutralização, há uma despolitização no espaço público e uma sobreposição do princípio do mercado sobre o princípio do Estado nos dizeres de Boaventura de Sousa Santos.

\footnotetext{
${ }^{26}$ FERREIRA, Bernardo. “O risco do...”, p. 57.

27 SCHMITT, Carl. “O conceito...”, p. 113.
}

A República de Weimar foi marcada pelo liberalismo, mas este quadro de neutralidade defendido pelo liberalismo entra em crise, atingindo, dessa feita, a questão do princípio da legalidade, fundamento do Estado Liberal, e Écio Otto Ramos Duarte retrata que:

A mudança do cenário histórico-institucional
provocado pela I Guerra Mundial produziu
faticamente no momento pós-guerra um
sentimento de desconfiança nos postulados
da neutralidade e formalidade da lei geral e
abstrata, inerentes à conformação do Estado
de direito legislativo, pois que estes princípios
tornavam-se incapazes de acompanhar
(realizar) as pretensões e finalidades
emergentes da necessária ampliação das
funções do Estado (....).

O quadro marcado pelo liberalismo no pós-guerra era uma sociedade extremamente desigual, na qual poucos detinham inúmeros privilégios, tendo em vista a fraqueza do Estado para tomar determinadas decisões. Assim, em meio a uma sociedade em que a miséria domina e a população passa por toda sorte de necessidades, regimes totalitários se instalam com muita facilidade, pois não havia política, e sem esta não existe democracia.

Ademais, o próprio capitalismo, no pósguerra, encontra-se em crise, o que clama por uma intervenção urgente do Estado no seio da economia, demonstrando mais uma vez o quão importante é a manutenção do espaço público e do ente estatal. Clémerson Merlin Clève demonstra os acontecimentos:

A partir desse momento, intensificado posteriormente com a segunda revolução industrial operada pela tecnologia eletrônica, o mercado passou a ser dominado por

${ }^{28}$ DUARTE, Écio Oto Ramos. Teoria do discurso e correção normativa do direito. São Paulo: Landy, 2003. p. 33. 
um número cada vez menor de empresas. Aparecem aqui o poder econômico e as regras do mercado. O capitalismo encarregado de destruir o próprio capitalismo (leia-se: mercado) por meio de técnicas cada vez mais sofisticadas. O capitalismo concorrencial entre em crise. A economia igualmente. O Estado é chamado a intervir. ${ }^{29}$

Observa-se que o liberalismo apesar de estabelecer uma preferência e dominação do princípio do mercado sobre o princípio do Estado, não consegue manter seu sistema, qual seja o capitalista, forte por muito tempo, havendo, depois de algum tempo, prejuízo ao próprio mercado.

A partir da crise no próprio mercado, analisa-se como fica a esfera do poder político, conseqüentemente, da democracia, pois se o mercado e o capital que foi preferido pela política liberal não conseguiram ser fortes e eficazes, necessitando da ajuda do Estado, imagina-se, então, como fica a política e os valores democráticos, que já eram preteridos.

Ora, a política, o espaço público e a própria democracia ficaram num rol de valores completamente esquecidos na modernidade. Daí, as suspeitas de Carl Schmitt em relação ao liberalismo e tais questionamentos são muito bem demonstrados por Bernardo Ferreira: "Longe de favorecer uma decisão política, a filosofia da história liberal levaria a evitá-la. (...) a perspectiva liberal conduziria a uma diluição das contraposições políticas no progresso econômico, antecipando a sua resolução no sentido pacífico do desenvolvimento histórico". ${ }^{30}$

${ }^{29}$ CLÉVE, Clèmerson Merlin. Atividade legislativa do poder executivo. 2. ed. São Paulo: Revista dos Tribunais, 2000. p. 38.

30 FERREIRA, Bernardo. “O risco do...”, p. 238.
O liberalismo dilui as diferenças existentes, faz com que o conceito de inimigo desapareça e tudo passa a ser resolvido sob um ângulo econômico e, conseqüentemente, a partir de interesses individuais.

Nesse ponto, apesar de Hannah Arendt possuir uma teoria diferente daquela apresentada por Carl Schmitt, ambos traçam caminhos diferentes, mas chegam a pontos comuns e, algumas vezes, constatam causas comuns. Por exemplo, Carl Schmitt prevê a grande dominação do mercado e Hannah Arendt verifica a existência das sociedades de consumo.

André Duarte, ao estudar o pensamento político de Hannah Arendt, demonstra que:

Nas modernas sociedades de trabalho e consumo, em que predominam atividades que exigem constante repetibilidade e concentração em si mesmas, o mundo se torna frágil e instável, pois as barreiras que deveriam garantir a estabilidade e permanência de suas instituições vão sendo constantemente devoradas, consumidas, pode-se dizer, enome dos ideais de abundância do crescimento e acumulação de riqueza. ${ }^{31}$

Assim, percebe-se que assuntos políticos e que dizem respeito ao bem comum são diluídos em meio a uma sociedade, na qual a grande preocupação é o consumo, o capital, ou seja, o mercado em si. Os próprios países não lutam mais por territórios, sua briga na atualidade é por mercados, e isso é evidenciado por Heinz Dieterich: “(...) a 'guerra econômica global' é pela repartição da riqueza planetária entre os poderosos. Antes se faziam guerras 'por territórios, hoje se fazem por mercados' (...)". ${ }^{32}$

\footnotetext{
${ }^{31}$ DUARTE, André. "Hanna Arendt...", p. 64.

32 DIETERICH, Heinz. Apud. LIMA, Abili Lázaro Castro. Globalização econômica, política e direito:
} 
Com a diminuição gradativa das fronteiras, há conseqüentemente a perda do espaço público e do referencial de inimigo na concepção schmittiana, qual seja, a de inimigo público. Nesse sentido, o que se observa é o aumento das sociedades massificadas, nas quais não existem diferenças, assim como inexiste qualquer debate sobre política, pois consoante Kenichi Ohmae: "As fronteiras políticas ainda existem, mas o que importa para as pessoas num mundo sem fronteiras é o atendimento de suas demandas de consumo". ${ }^{33}$

O que se pode observar é que o pessimismo de Carl Schmitt em relação ao liberalismo em muito se assemelha ao pessimismo de Max Weber em relação ao Iluminismo. Max Weber não acredita que o processo de desencantamento do mundo, o que trouxe a racionalização. Para muitos, esta transformação seria responsável tão-somente por benefícios, mas o sociólogo, já ao seu tempo, conseguia observar alguns prejuízos que a sociedade iria enfrentar no decorrer de sua evolução. Nesse sentido, encontra-se o ensinamento de Alberto Tosi Rodrigues quando estuda o pensamento de Max Weber e demonstra que, na visão weberiana, "O Estado nacional é também burocratização da vida, estagnação criativa, freio à liberdade, gaiola de ferro. Weber é um realista e um pessimista depressivo na contemplação filosófica". ${ }^{34}$

análise das mazelas causadas no plano político-jurídico. Porto Alegre: Sergio Antonio Fabris Editor, 2002. p. 155.

33 OHMAE, Kenichi. Apud. LIMA, Abili Lázaro Castro. “Globalização...”, p. 195.

${ }^{34}$ RODRIGUES, Alberto Tosi. Max Weber, o último dos clássicos. In: OLIVEIRA, Manfredo. AGUIAR, Odilon Alves. SAHD, Luiz Felipe Netto de Andrade e Silva (Org.). Filosofia política contemporânea. Petrópolis: Vozes, 2003. p. 54.

\section{A DIFERENÇA COMO FUNDAMENTO DA POLÍTICA}

Observada, ainda que rapidamente, a teoria schmittiana a respeito da política, adentrar-se-á no estudo da política sob a óptica de Chantal Mouffe. Esta prega por uma democracia radical, que na descrição de Katya Kozicki “(...) pressupõe a abertura, o reconhecimento da contingência, a aceitação de que os sentidos são plurais, irredutíveis a uma única possibilidade significativa". ${ }^{35}$

Ora, é com base na diferença que a democracia radical se consolida, ou seja, justamente no reconhecimento do outro. Nesse sentido, leciona Katya Kozicki: "Cada indivíduo, cada luta por objetivos políticos distintos só adquire sentido em virtude de algo que se opõe a eles e lhes significa, a partir de fora. É neste reconhecimento do outro, da obtenção do sentido através do seu elemento externo constitutivo, conforme já mencionado, que a democracia ganha vida e forma". ${ }^{36}$

A teoria da democracia radical de Chantal Mouffe acaba encontrando relação com a teoria de Carl Schmitt, quando este combate o liberalismo. Chantal Mouffe reconhece expressamente os problemas que advieram do liberalismo e demonstra que "É a incapacidade do pensamento liberal para compreender a sua natureza e o carácter irredutível do antagonismo que explicam

${ }^{35}$ KOZICKI, Katya. A política na perspectiva da filosofia da diferença. In: OLIVEIRA, Manfredo. AGUIAR, Odilon Alves. SAHD, Luiz Felipe Netto de Andrade e Silva (Org.). Filosofia política contemporânea. Petrópolis: Vozes, 2003. p. 142.

36 Ibid, p. 143. 
a impotência da maioria dos teorizadores políticos na situação atual (...)". ${ }^{37}$

O Liberalismo acaba destruindo as diferenças e, como pôde ser percebido na teoria schmittiana, torna o inimigo desconhecido. Para a democracia radical, o outro precisa ser necessariamente reconhecido, pois é a partir da diferença que a teoria é construída.

Ainda no que tange ao liberalismo, cabe fazer uma diferenciação que existe dentro da teoria liberal. Existem duas vertentes do liberalismo, o econômico e o político. Segundo Claúdio Pereira de Souza Neto referindo-se, primeiramente, ao liberalismo político e, logo após, ao econômico, elucida que "O primeiro está preocupado com a garantia de direitos e liberdades fundamentais: o segundo com a não intervenção do estado na esfera econômica". ${ }^{38}$

É a partir dessa conceituação do liberalismo em econômico e político, que Chantal Mouffe reconhece a importância do liberalismo político e afirma categoricamente que “(...) o liberalismo político é uma (sic) componente fundamental de qualquer projecto de democracia plural e radical". ${ }^{39}$

Logo, percebe-se que na teoria da democracia radical não há um combate contra o liberalismo por inteiro, mas somente uma refutação ao liberalismo econômico, uma vez que o liberalismo político é aceito e, além disso, é tido como elemento imprescindível para a realização de uma democracia.

\footnotetext{
${ }^{37}$ MOFFE, Chantal. “O regresso...”, p. 12.

${ }^{38}$ SOUZA NETO, Cláudio Pereira. Teoria constitucional e democracia deliberativa: um estudo sobre o papel do direito na garantia das condições para a cooperação na deliberação democrática. Rio de Janeiro: Revovar, 2006.p. 21.
}

39 MOFFE, Chantal. “O regresso...”, p. 141.
Observa-se a partir daí que a democracia necessita da política para a sua sobrevivência, pois é por meio da política que se poderá observar as diferenças necessárias para a concretização e efetivação do que vem a ser a democracia. Nesse sentido, Chantal Mouffe deixa claro que "(...) a actual indistinção de fronteiras políticas entre esquerda e direita pode ser prejudicial para a política democrática, uma vez que impede a constituição de identidades políticas distintas". ${ }^{40}$

Ora, ter uma identidade é de fundamental relevância para que o homem se torne um ser político, pois é a partir da própria identificação que se poderá observar o outro e analisar, assim, as diferenças existentes. Quando o homem passa a ter ciência do que ele é, de como ele pensa, acaba atingindo um grau maior na escala da conscientização, pois sabe e tem certeza de como articular e defender suas opiniões.

O liberalismo econômico acaba destruindo as diferenças, pois consegue transformar todos os problemas em questões econômicas, acaba, portanto, uniformizando tudo que era diferente. Boaventura de Sousa Santos demonstra muito bem como ocorre a técnica de transformar as diferenças em igualdade na modernidade:

O sistema comum de medida baseia-se numa concepção de espaço e tempo homogêneos, neutros, lineares, que servem de menor denominador comum a partir do qual se definem as diferenças relevantes. (...) Com base nesta concepção é possível, por um lado, separar a natureza da sociedade e, por outro, estabelecer um termo de comparação quantitativo entre interações sociais massivas e

\footnotetext{
${ }^{40} \mathrm{Ibid}$, p. 16.
} 
muito diferenciadas. As diferenças qualitativas entre elas ou são ignoradas ou são reduzidas aos indicadores quantitativos que delas podem dar conta aproximadamente. O dinheiro e a mercadoria são as concretizações mais puras do sistema comum de medidas. ${ }^{41}$

Chantal Mouffe demonstra o perigo existente em sociedades em que não existe a diferença: "A ausência de uma fronteira política, é sintoma de um vazio que pode pôr em perigo a democracia, porque esse vazio proporciona um terreno que pode ser ocupado pela extrema-direita para articular novas identidades políticas antidemocráticas". ${ }^{42}$

Assim, sociedades sem diferenças políticas é uma porta aberta para a instauração de regimes totalitários, uma vez que a população não terá qualquer consciência de valores políticos. O pluralismo acaba sendo um requisito essencial para o acontecimento da democracia e para que a pluralidade exista, é necessário que haja a existência e o respeito à diferença.

É claro que ao se falar em diferença não se está falando em guerra, mas como denota José Roberto Vieira, "De fato, democrático é, sem dúvida, o convívio pacifico das discordâncias e a convivência serena das divergências (...); e diverso não calharia ser, porque o conflito é intimamente próprio do humano". ${ }^{43}$ Assim, onde há um ser humano, existirão diferenças,

${ }^{41}$ SANTOS, Boaventura de Souza. Reinventar a democracia: entre o pré-contratualismo e o póscontratualismo. In: OLIVEIRA, Francisco. PAOLI, Maria Célia (Org.). Os sentidos da democracia: políticas do dissenso e hegemonia global. 2. ed. Petrópolis: Vozes, 2000. p. 85-86.

${ }^{42}$ Id ibid.

${ }^{43}$ VIEIRA, José Roberto. República e democracia: óbvios ululantes e não ululantes. In: Revista da Academia de Direito Constitucional. Volume 4. Ano 2003. p. 95. haverá discordâncias, o que é natural, pois se assim não o fosse, estar-se-ia diante de uma realidade produzida artificialmente.

Ao contrário do que foi afirmado acima, os liberais pós-iluministas demonstram uma realidade diferente, é o que retrata Zygmunt Bauman quando leciona que "As diferenças nascem quando a razão não está inteiramente desperta ou voltou a adormece. Esse era o credo implícito que emprestava credibilidade à clara confiança que os liberais pósiluministas depositavam na capacidade dos indivíduos para a imaculada concepção". ${ }^{44}$ A teoria liberal acaba desmerecendo a diferença entre os homens, colocando em pauta que o homem racional é aquele cujas diferenças não existem.

Daí a importância de se estar atento às diferenças que existem na sociedade $\mathrm{e}$ escutar atentamente àqueles que clamam pela diferença. No Brasil, conforme descreve Francisco de Oliveira é muito difícil que se possa pensar na existência de uma democracia, pois conforme descreve o citado sociólogo:

Todo o esforço de democratização, de criação de uma esfera pública, de fazer política, enfim, no Brasil, decorreu, quase por inteiro, da ação das classes dominadas. Política no sentido em que a definiu Rancière, já citado: a da reivindicação da parcela dos que não têm parcela, a da reivindicação da fala, que é, portanto, dissenso em relação aos que têm direito às parcelas, que é, portanto, desentendimento em relação a como se reparte o todo, entre os que têm parcelas ou partes do todo e os que não têm nada. ${ }^{45}$

${ }^{44}$ BAUMAN, Zygmunt. Modernidade líquida. Rio de Janeiro: Jorge Zahar, 2001. p. 193.

${ }^{45}$ OLIVEIRA, Francisco. Privatização do público, destituição da fala e anulação da política: o totalitarismo neoliberal. In:OLIVEIRA, Francisco. PAOLI, Maria 
Ora, é somente com base na diferença que se pode construir uma verdadeira democracia, e Chantal Mouffe em sua obra "O regresso do político" deixa tal idéia evidente e diz que "A ideia de um consenso perfeito, um desejo colectivo harmônico, tem portanto, de ser abandonada e a permanência dos conflitos e antagonismo aceite". ${ }^{46}$ E ser democrático é justamente isso, aceitar o outro como ele é, não tentar impor sua opinião, respeitando as idéias e crenças do outro.

\section{CONCLUSÃO}

Ao final da leitura, pode-se concluir a respeito da importância da esfera pública na sociedade, uma vez que será em tal âmbito que se concretizarão as questões políticas. Assim sendo, por meio da política, que fundamentalmente necessita da diferença para o seu acontecimento, é que será realizada a democracia.

Ademocracia, por sua vez, é o instrumento que assegura o respeito aos direitos do homem, fazendo, por exemplo, que os direitos das minorias sejam protegidos. Nesse sentido, diante da realidade existente, a sociedade deve buscar urgentemente o retorno da política, pois, com o esquecimento desta, haverá um prejuízo irreparável ao estágio evolutivo em que se encontra a humanidade e, com certeza, haverá um retrocesso na garantia de direitos, que são conquistados e preservados por meio da política.

Célia (Org.). Os sentidos da democracia: políticas do dissenso e hegemonia global. 2. ed. Petrópolis: Vozes, 2000. p. 60 e 61.

${ }^{46}$ MOFFE, Chantal. “O regresso...”, p. 140.

\section{REFERÊNCIAS BIBLIOGRÁFICAS}

ARENDT, Hannah. A condição humana. 10. ed. São Paulo: Forense Universitária, 2005.

BAUMAN, Zygmunt. Modernidade líquida. Rio de Janeiro: Jorge Zahar, 2001.

CLÉVE, Clèmerson Merlin. Atividade legislativa do poder executivo. 2. ed. São Paulo: Revista dos Tribunais, 2000.

CHUEIRI, Vera Karam. Nas trilhas de Carl Schmitt (ou nas teias de Kafka): soberania, poder constituinte e democracia (radical). In: FONSECA, Ricardo Marcelo (Org). Repensando a teoria do estado. Belo Horizonte: Fórum, 2004.

DUARTE, André. Hanna Arendt e a modernidade: esquecimento e redescoberta da política. In: CORREIA, Adriano. Transpondo o abismo: Hanna Arendt e a filosofia e a política. Rio de Janeiro: Forense Universitária, 2002.

FERREIRA, Bernardo. O risco do político: crítica ao liberalismo e teoria política no pensamento de Carl Schmitt. Belo Horizonte: Editora UFMG, 2004.

GIDDENS, Anthony. As conseqüências da modernidade. São Paulo: UNESP, 1991.

GÓMEZ, Enrique Serrano. Consenso y conflicto - Schmitt, Arendt y la definición de lo político. México: Centro de Estudios de Política Comparada, AC, 1998.

LIMA, Abili Lázaro Castro. Globalização econômica, política e direito: análise das mazelas causadas no plano político-jurídico. Porto Alegre: Sergio Antonio Fabris Editor, 2002.

MOUFFE, Chantal. O regresso do político. Lisboa: Gradiva, 1996.

OLIVEIRA, Francisco. Privatização do público, destituição da fala e anulação da política: o totalitarismo neoliberal. In:OLIVEIRA, Francisco. PAOLI, Maria Célia (Org.). Os sentidos da democracia: políticas do dissenso e hegemonia global. 2. ed. Petrópolis: Vozes, 2000.

OLIVEIRA, Manfredo. AGUIAR, Odilon Alves. SAHD, Luiz Felipe Netto de Andrade e Silva (Org.). Filosofia política contemporânea. Petrópolis: Vozes, 2003. 
SANTOS, Boaventura de Sousa. A crítica da razão indolente: contra o desperdício da experiência. São Paulo: Cortez, 2005.

SANTOS, Boaventura de Sousa. Pela mão de alice: o social e o político na pós-modernidade. 10. ed. São Paulo: Cortez, 2005.

SANTOS, Boaventura de Sousa. Reinventar a democracia: entre o pré-contratualismo e o pós-contratualismo. In: OLIVEIRA, Francisco. PAOLI, Maria Célia (Org.). Os sentidos da democracia: políticas do dissenso e hegemonia global. 2. ed. Petrópolis: Vozes, 2000.

SCHMITT, Carl. O conceito do político. Petrópolis: Vozes, 1992.
SOUZA NETO, Cláudio Pereira. Teoria constitucional e democracia deliberativa: um estudo sobre o papel do direito na garantia das condições para a cooperação na deliberação democrática. Rio de Janeiro: Revovar, 2006.

VIEIRA, José Roberto. República e democracia: óbvios ululantes e não ululantes. In: Revista da Academia de Direito Constitucional. Volume 4. Ano 2003.

WEBER, Max. Ensaios de sociologia. 5.ed. São Paulo: LTC Editora, 1982.

WINCKLER, Silvana. Contribuições de Hanna Arendt para a teoria política. In: WOLKMER, Antonio Carlos. 